\title{
Categorización cualitativa para diseñar marketing semiótico estratégico en consumo sustentable: storytelling y universitarios
}

Qualitative categorization for the design of strategic semiotic marketing in sustainable consumption: storytelling and university consumption

Categorização qualitativa para projetar marketing semiótico estratégico no consumo sustentável: contação de histórias e estudantes universitários

Andrea Estupiñán Villanueva

Benemérita Universidad Autónoma de Puebla, México

andrea.estupinan@correo.buap.mx https://orcid.org/0000-0002-9705-5440

Edith Molina Carmona

Benemérita Universidad Autónoma de Puebla, México

edith.molina@correo.buap.mx https://orcid.org/0000-0002-2047-337X

\section{Resumen}

Los diversos esfuerzos por detener el daño ambiental en el mundo deben ir más allá de hacer conciencia y enfocarse a desarrollar contenido comunicativo que genere acciones y cambios conductuales de los individuos. En este trabajo la comunidad conformada por universitarios fue utilizada para identificar categorías de análisis cualitativas aplicables en el desarrollo de estrategias que impulsen acciones que favorezcan el consumo sustentable. El objetivo fue definir el tipo de estrategias que pudieran significar empatía y por ende, efectividad para el envío de mensajes que conlleven el actuar a favor del medio ambiente. Se recurrió a la fenomenología, al pragmatismo, al interaccionismo simbólico y al marketing 


\section{Revista Iberoamericana de las Ciencias Sociales y Humanísticas}

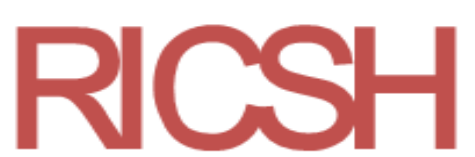

ISSN: $2395-7972$

semiótico utilizando como base metodológica entrevistas en profundidad realizadas a sujetos en etapa universitaria. Los diferentes códigos que emanaron para dar lugar a los contenidos efectivos en vías de acciones sustentables, fueron conciencia, conductas, interacciones sociales, impacto, persuasión, selectividad, satisfacción de necesidades y convivencia. Con base en ello se propuso desarrollar historias que narraran mensajes a través de diferentes piezas de storytelling como una opción viable ante el tipo de contenido comunicativo empático con la comunidad de consumo elegida, y la urgencia de respuesta que se requiere por parte de los individuos. Se concluyó que las técnicas de alto impacto logran persuadir al público receptor hacia tomar elecciones de acción a favor de satisfacer sus necesidades sin poner en riesgo la integridad de terceros ni futuras generaciones.

Palabras clave: universitarios, categorías cualitativas, comportamiento del consumidor, símbolos, impacto ambiental.

\section{Abstract}

The various efforts to stop environmental damage in the world must go beyond raising awareness and focusing on developing communicative content that generates actions and behavioral changes for individuals. In this work, the community made up of university students was used to identify qualitative analysis categories applicable in the development of strategies that promote actions that favor sustainable consumption. The objective was to define the type of strategies that could mean empathy and, therefore, effectiveness for sending messages that involve acting in favor of the environment. Phenomenology, pragmatism, symbolic interactionism and semiotic marketing were resorted to using in-depth interviews with subjects at the university stage as a methodological basis. The different codes that emanated to give rise to effective content in the process of sustainable actions were awareness, behavior, social interactions, impact, persuasion, selectivity, satisfaction of needs and coexistence. Based on this, it was proposed to develop stories that narrated messages through different pieces of storytelling as a viable option before the type of communicative content empathetic with the chosen consumer community, and the urgency of response required by individuals. It was concluded that high impact techniques succeed in persuading the receiving public to make action choices in favor of satisfying their needs without putting at risk the integrity of third parties or future generations. 


\section{Revista Iberoamericana de las Ciencias Sociales y Humanísticas}

Keywords: university students, qualitative categories, consumer behavior, symbols, marketing, environmental impact.

\section{Resumo}

Os diversos esforços para conter os danos ambientais no mundo devem ir além da conscientização e focar no desenvolvimento de conteúdos comunicativos que gerem ações e mudanças de comportamento nos indivíduos. Neste trabalho, a comunidade formada por estudantes universitários foi utilizada para identificar categorias de análise qualitativa aplicáveis no desenvolvimento de estratégias que promovam ações que favoreçam o consumo sustentável. O objetivo foi definir o tipo de estratégias que poderiam significar empatia e, portanto, eficácia no envio de mensagens que envolvam atuar em prol do meio ambiente. Foram utilizados fenomenologia, pragmatismo, interacionismo simbólico e marketing semiótico, tendo como base metodológica entrevistas em profundidade com sujeitos em estágio universitário. Os diferentes códigos que emanaram para dar origem a conteúdos efetivos em formas de ações sustentáveis, foram consciência, comportamentos, interações sociais, impacto, persuasão, seletividade, satisfação de necessidades e convivência. A partir disso, propôs-se desenvolver histórias que narrem mensagens por meio de diferentes narrativas como uma opção viável diante do tipo de conteúdo comunicativo empático com a comunidade de consumidores escolhida e da urgência de resposta que é exigida dos indivíduos. Concluiu-se que as técnicas de alto impacto conseguem persuadir o público receptor a fazer escolhas de ações em prol da satisfação de suas necessidades, sem colocar em risco a integridade de terceiros ou das gerações futuras.

Palavras-chave: estudantes universitários, categorias qualitativas, comportamento do consumidor, símbolos, impacto ambiental.

Fecha Recepción: Septiembre 2019

Fecha Aceptación: Julio 2020 


\section{Introducción}

El estudio del comportamiento del consumidor se ha asociado con diferentes teorías y aportes científicos como los de Sha, May y Londerville (2007) o Ajzen y Fishbein (1980) así como Rodríguez y Rabadán (2015), quienes entre analizar actitudes, conductas, factores psicológicos, personales, sociales y de mercado, profundizan en la forma en la cual se puede construir un proceso encaminado a la investigación para la implementación de estrategias fundamentadas en métodos capaces de ser aplicados en diferentes contextos de comunidades de consumo similares.

Paris (2015), Mickelsson (2017) y González (2016) aseguran que los elementos gráficos y formales son determinantes al momento de permear y tomar la decisión de compra, siendo en este punto donde se interrelaciona el marketing con la semiótica al momento de diseñar mensajes dirigidos hacia cambios de conducta entre individuos con ciertas semejanzas y entornos afines. En esta ocasión, el estudio apunta hacia los universitarios mexicanos de instituciones públicas en México. Para ello, se tomaron estudios precedentes dentro de la Benemérita Universidad Autónoma de Puebla (BUAP) y como muestra a la Facultad de Ciencias de la Comunicación (FCCom), para establecer una metodología que impulse el consumo sustentable entre sus miembros.

Así, los estudios relacionados con el comportamiento de los individuos y su relación temática con el entorno, se han abordado desde hace varias décadas (Schiffman y Kanuk, 2005). El consumo sustentable revisa, analiza y propone diferentes enfoques relacionados con la forma en que las comunidades deciden consumir, lo que consumen y la manera en que lo hacen (Giddens, 2014), por lo que se indaga la manera en que el marketing semiótico establece estrategias para promover el consumo de mercancías sin dañar el entorno, usando diferentes elementos simbólicos reconocibles por los individuos (Alonso, 2008). Esto es, conformar procedimientos que formen metodologías para establecer las etapas que impacten en un consumo consciente (Saldívar, et al, 2002). Aquí se propone una categorización cualitativa a través de una guía de entrevista en profundidad diseñada con base en la revisión de literatura aplicada a un miembro de cada uno de los sectores de la comunidad universitaria de la BUAP que permita definir la estructura de una storytelling como estrategia hacia el consumo sustentable. 


\section{Método}

\section{Consumo y sustentabilidad}

El egoísmo de mujeres y hombres, no tiene medida. Bur (2013) refiere al desarrollo sustentable como las actividades que no deterioran los elementos que lo hacen posible, conservan el medio ambiente y favorecen el bienestar de las personas, se traduce en un crecimiento económico que promueve la equidad social y establece una relación no destructiva con la naturaleza. Ante esto, Löbler (2017) añade que el ser humano adolece de un antropocentrismo extremo siendo urgente no solo que comprenda, sino que admita llevar a cabo acciones que favorezcan la calidad de vida para las generaciones futuras, y por lo tanto la naturaleza seguramente puede sobrevivir sin los humanos, pero estos no podrán hacerlo sin la naturaleza (Löbler, 2017). Se han hecho diferentes esfuerzos por influir en la conducta sobre el consumo y la relación de éste con el bienestar holístico, sin un resultado favorable. Incluso Löbler (2017) refiere la necesidad de establecer una relación de marketing entre la naturaleza y el ser humano. González (2016) por su parte, ahonda en que deben implementarse herramientas del mercado que fomenten las prácticas hacia un consumo sustentable.

La cuestión es conocer la manera en que una estrategia puede representar el motivo por el que funcionen los mensajes construidos en pro de un cambio de conducta. González (2016) enfatiza que deben proponerse mecanismos para "apoyar el logro de los objetivos de desarrollo sostenible sobre los residuos alimentarios” (p. 185).

Debe considerarse que la producción hoy es más que en serie y la generación de productos atiende cada vez más a fragmentos de audiencias dispuestas a gastar no solo su dinero, sino su vida misma por la comodidad y prontitud del consumo (González, 2016).

\section{Comportamiento de la comunidad de consumo universitaria}

Como se revisó anteriormente, los hábitos de los consumidores universitarios afectan el entorno, por lo que, debiera hacerse un esfuerzo por comprender los motivos del comportamiento de estas comunidades de consumo, así como los factores y elementos que pueden apoyar en la decisión de compra y generar acciones para afectar lo menos posible el ambiente. 
En el año 2013 se llevó a cabo un estudio dentro de la Benemérita Universidad Autónoma de Puebla (BUAP) donde se identificó un problema severo de consumo y desecho de unicel donde los individuos actuaban de manera poco consciente. El objetivo fue distinguir la conducta que tenía la comunidad universitaria con respecto al uso, consumo y desecho de residuos. Este estudio se apoyó en un proyecto surgido en el año 2007 dentro de la Facultad de Ciencias de la Comunicación y desarrollado a través del Cuerpo Académico Comunicación y Sociedad. Bajo el nombre Megaproyecto Universidad y Medio Ambiente (UMA) se logró identificar, tanto la percepción que tenía la comunidad acerca del cuidado del entorno, como definir los elementos que debían aplicarse para generar propuestas e influir en la conducta de los universitarios respecto a ese tópico.

La información obtenida mostró, no solo la falta de conciencia de los actos del uso, consumo y desecho del unicel, sino lo que desechan y la forma en que lo hacían. Mediante la observación directa dentro de las facultades de Ciudad Universitaria de la BUAP se distinguió, por un lado, la falta de identidad en el diseño de los mensajes dirigidos al propósito de orientar e informar sobre el tema, y por el otro, la ausencia de hábitos sobre los materiales en los que se consumen los alimentos. Ante ello, se hizo evidente la necesidad de identificar los factores que influyen en el comportamiento de los consumidores, así como el impacto de cada uno de ellos en esa toma de decisiones (González, 2016), ya que pareciera ser que no es una de sus prioridades.

Así, en el año 2013 se da seguimiento al problema abordado por UMA y se toma la línea del consumo de unicel en Ciudad Universitaria de BUAP. Se identificó que se consumían alimentos en recipientes desechables que generaban a la semana más de 270,000 piezas de unicel. Esto aunado a las enormes cantidades de PET, plástico, aluminio, cartón, papel, residuos electrónicos y productos tóxicos emanados de laboratorios de la Institución. Un foco rojo de contaminación integral en una comunidad educada en valores de responsabilidad social y respeto por su entorno. 


\section{Postura teórico-estratégica hacia el comportamiento social: categorías y códigos de análisis sobre el problema}

Para profundizar en el presente tema se hizo una búsqueda digital basada en las categorías consumo sustentable y marketing semiótico. Entre las generalidades encontradas están las mencionadas por Fernández (2018, quien retoma a Ajzen y Fishbein, 1980) quien asocia la teoría de la acción razonada con el análisis de la actitud y la conducta sobre dicho comportamiento. Este autor resalta que la elección de los individuos atiende a factores psicológicos, personales, sociales y de mercado con los que se simpatiza. Su y Chang (2018) mencionan la importancia de elementos visuales ya sea gráficos o creados en los referentes del consumidor y sostiene que los textos de este tipo fomentan la lealtad de marca en mercados segmentados.

En esta misma línea, se ha abordado el tema de los significados locales y globales en consumidores, dividiéndolos en tres tipos de dimensión de consumidores: subcultivo, neotribu y comunidad de marca, esto gracias a un análisis semiótico de los contenidos de mensajes enviados a través de medios digitales (Rodríguez y Rabadán, 2015). A partir de esto, se resalta la importancia de considerar comunidades de consumo basadas no solo en una dimensión que caracterice a las audiencias (Rodríguez y Rabadán, 2015) sino en comunidades que cuentan con una dimensión múltiple en la manera en que perciben los significados y, por ende, actúan en relación con ello.

Los estudios enfocados a la percepción sensorial del consumidor han utilizado los insights o autofotos, como posibles desestabilizadores de la percepción del consumidor al momento de elegir una marca (Rokka y Canniford, 2016). Esta técnica ha sido ampliamente considerada en el estudio del marketing semiótico (Presi, Maehle y Kleppe, 2016) definiendo a los insights como ricos textos visuales y auditivos que se estudian a partir de cuatro tipos de análisis: descriptivo, de respuesta, formal y temático politextual que son decodificados por los tres tipos de dimensiones de consumidores.

Barrio, (2017) asocia a los insights con categorías como actitud y conducta, que, relacionados con los elementos audiovisuales, definen los diferentes tipos de consumidores a partir de la manera en que generan la interpretación de los significados. Otros autores destacan el uso de otra diversidad de metodologías en el marketing semiótico (Henninger, Alevizou y Oates, 2016) principalmente cuando se trata de estudiar el consumo sustentable 
a través de nuevas metodologías, donde los consumidores asocian ciertos aspectos de valor en los significados con los que se van encontrando durante el proceso de consumo.

Otras investigaciones han abordado el estudio de símbolos y significados enfatizando el papel del diseño en la construcción de los mensajes (Gurrieri, Govan y Cherrier, 2016) y su uso en la interpretación, persuasión y preferencia hacia un producto (Le Roux, Thébault, Roy y Bobrie, 2016). Maddock y Colina (2016) abordaron la importancia de los productos con la manera en que son anunciados a través de un análisis de imágenes visuales y referentes auditivos vinculados con alimentos. Martin y Väistö (2016) recomiendan que es necesario utilizar más la teoría del consumo para entender el vínculo entre aspectos hedónicos, estéticos y cognitivo-racionales del consumo sustentable ya que la lectura socio-semiótica es un recurso que favorece la confianza de los consumidores hacia los cambios en sus acciones, esto a través de las estructuras semánticas que presenten historias empáticas a sus percepciones (Cid, 2002).

\section{Marketing estratégico sustentable: el storytelling y su categorización cualitativa}

Después de llevar a cabo la revisión de textos y casos relacionados con el tema, el propósito es establecer los parámetros para el contenido que debe conformar la estrategia que persuada hacia el consumo sustentable. También identificar los elementos simbólicos que deben conformar esa estrategia. Y finalmente, establecer los parámetros de evaluación de la estrategia elegida para una comunidad de consumo dentro de una universidad pública en México.

Para ello, se planteó el interés sobre definir los elementos simbólicos significativos que deben incluirse en una estrategia de marketing semiótico para fomentar el consumo sustentable entre la población de comunidades universitarias. Esto incluye los códigos de la categoría que son: tipo de públicos, objetivos, tácticas y estrategias. Se retoman aseveraciones dentro de lo manifestado en la categoría de marketing semiótico para establecer que los mensajes deben atender determinado tiempo de reflexión y pregnancia para permear en la mente del consumidor. También, el contenido del mensaje debe abarcar cuestiones en las cuales se manifiesten vivencias, tipo storytelling en donde se muestren casos empáticos con el público de la Facultad. 


\section{Revista Iberoamericana de las Ciencias Sociales y Humanísticas}

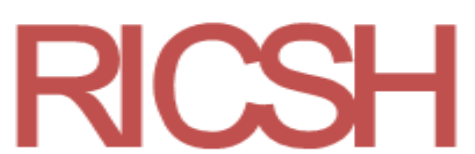

ISSN: $2395-7972$

Esto es posible al elegir estrategias que fomenten la importancia en temas como la pertinencia social, el impulso de comportamientos basados en valores y en la mirada hacia la búsqueda de soluciones a estos problemas. Esta situación ha llevado a cuestionar las formas en que se está haciendo llegar la información sobre la conciencia de la sustentabilidad, del consumo y del posible cambio de conducta, obligando a revisar las opciones de mayor innovación en comunicación consciente sobre estas temáticas.

De este modo, la propuesta parece tender hacia hacer este abordaje desde los códigos simbólicos, culturales y arquetipos, de hecho, existen varios estudios que apelan a la necesidad de trabajar enfoques semióticos para la comprensión del marketing y su relación con distintas variables del marketing. Mickelsson (2017) aborda la vinculación entre temas diversos como la sustentabilidad y el marketing semiótico en comunidades de consumo (Rodríguez y Rabadán, 2015), como es la de los jóvenes universitarios. La construcción de narrativas basadas en marketing semiótico estratégico sobre productos relacionados con el consumo sustentable requiere de un espacio en la investigación que permita asociar a los actores con el consumo y encontrar la manera en que coincida la semiótica con el ámbito comercial de la imagen del marketing. Esto, desde el consumo, debe implicar conductas estratégicas favorables al entorno y al impacto social (Raghda, 2013).

Así, en la ardua tarea de sensibilizar y concientizar a las organizaciones (Peterson y Lunden, 2016), es necesario fundamentar los pasos a seguir para construir propuestas que apliquen la construcción simbólica y la asociación de símbolos empáticos con el consumo consciente de productos amigables con el medio ambiente. Esto es, rediseñar métodos que fomenten prácticas de consumo sustentable. Ante esto, se propone la estrategia denominada storytelling, una historia hecha de tal manera que genera empatía con el receptor al interiorizar, comprender y crear significados (Salmón, 2008) gracias a los referentes que tienen de determinadas situaciones, con lo que se sienten identificados y por ende, es más factible persuadirlos hacia un cambio en sus comportamientos. Esta es una innovación de marketing semiótico hacia el fomento de prácticas socialmente favorables con el entorno.

Salmón (2008) refiere que el storytelling establece vínculos emocionales con los consumidores por la relación simbólica que manifiestan. Es una herramienta de investigación cualitativa para describir momentos personales, situaciones con detalles que aportan elementos en la elaboración de mensajes cargados de definida intencionalidad por parte de los emisores. Debe considerarse que, como cualquier herramienta de esta naturaleza 


\section{Revista Iberoamericana de las Ciencias Sociales y Humanísticas}

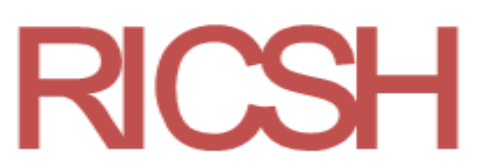

ISSN: 2395 - 7972

cualitativa, está sometido a la comprensión interpretativa de la experiencia humana (Durán, 2012).

El abordaje de esta herramienta no solo de investigación, sino estratégica, permite identificar significados emanados de los propios informantes. La aplicación del storytelling es así una transferencia de conocimiento del investigador al lector que logra la creación de historias empáticas para la adopción de conductas favorables hacia el consumo sustentable (Stake, 2005).

Las categorías utilizadas para esta investigación cualitativa fueron la fenomenología, el pragmatismo y el interaccionismo simbólico, todas ellas desde la mirada social que permitiera indagar desde la información otorgada por cada individuo entrevistado, categorías que apoyarán en la construcción de una estrategia efectiva, empática, funcional, propositiva, y factible. Para la construcción de esta estrategia, se consideraron unos enunciados sobre marketing semiótico y consumo sustentable, para finalmente, una dimensión de la categoría consumo sustentable, que es más descriptiva y halla conductas específicas, ésta es la de acciones sustentables.

El perfil de los entrevistados fue de representación de sectores dentro de la FCCom, esto es un académico, un no académico y un estudiante. La guía de preguntas para entrevistas en profundidad que se les aplicó, dio lugar a la estrategia de storytelling como una opción de promoción hacia el consumo sustentable. De este modo se entenderán de la siguiente manera: A1 es Administrativo, E1 es Estudiante, y D1 es Docente.

Así, la entrevista giró en torno al tema de la relación del comportamiento de los miembros universitarios, donde el marketing semiótico es un método para alcanzar el propósito de un cambio hacia el consumo sustentable. Se emplearon 31 preguntas. Los ejes de las entrevistas a partir de las categorías se muestran en la Tabla 1.

Tabla 1. Guía de Entrevista en Profundidad

Categoría: Fenomenología.- Relación de acciones, sociedad, e individuos

Categoría: Pragmatismo.- Interpretación de su realidad

Categoría: Interaccionismo simbólico.-Consenso y significados

Categoría: Consumo sustentable (Actitudes hacia el consumo y sustentabilidad)

Categoría: Marketing semiótico (Mensajes sobre consumo sustentable)

Categoría: Acciones sustentables (elementos para establecer estrategias)

Fuente: Elaboración propia, 2018. 
Los hallazgos emanados de la aplicación de este instrumento cualitativo se detallan a continuación a través de un extracto del análisis e interpretación de los resultados encontrados en la aplicación de las entrevistas en profundidad. Se distinguen, durante la redacción, las citas textuales de lo narrado por los individuos, así como el cruce con el constructo teórico. De este modo, se va describiendo el esbozo teórico que sustenta el análisis y la importancia de la relación entre las categorías.

\section{Resultados}

\section{Interpretación de resultados de la investigación cualitativa}

Cada una de las entrevistas se llevó a cabo dentro de instalaciones universitarias. Los temas se fueron abordando conforme los sujetos las iban manifestando en sus respuestas. Por tal motivo, si bien se abordaron todas las categorías, éstas fueron resueltas de manera indistinta en vías de provocar una narración más libre por parte de los entrevistados. Los resultados emanados de la categoría de fenomenología, muestran tres manifestaciones de la conciencia intencional que a continuación se explican en la Tabla 2:

Tabla 2. Manifestaciones de la conciencia intencional

\begin{tabular}{|l|l|l|}
\hline \multicolumn{3}{|c|}{ Intencionalidad (propósito) = intencional = vivencia intencional } \\
(enmarcada en un tiempo y espacio)
\end{tabular}

Fuente: Elaboración propia, 2018. Basada en Martínez, 1996 y Osorio, 1998.

Los resultados emanados de la categoría de fenomenología, muestran tres manifestaciones de la conciencia intencional (Martínez, 1996): conciencia actual, potencial y atencional, reconociendo que las vivencias o fenómenos, son lo que conforman los tipos de conciencia (Osorio, 1998).

La intencionalidad es la característica más importante de la conciencia intencional (Husserl, 1998) y la manifestación de las experiencias se manifiestan en la información que se recaba de las vivencias (Berger y Luckmann, 2005). A continuación, se definen los hallazgos a través de los códigos de la categoría de fenomenología: 
a) Conciencia actual E1 menciona "lo que hacemos nosotros los estudiantes es comprar dentro de la universidad y no exigimos o no decimos pues no me sirvas en el unicel o no voy utilizar el popote, la pajilla como le llamen ooo los cubiertos así no porque tampoco nosotros pues traemos nuestros cubiertos o nuestro lonche”.

b) Conciencia potencial es el fondo de la vivencia de los hechos, por ejemplo, E1 refiere que "Más que nada el unicel, el unicel... pues en general se usa en la universidad y me parece que en todos lados para toda la comida, las bebidas, incluso también los cubiertos que son de plástico y así, no son, aunque digan que si algunas fábricas o empresas no son para nada reutilizables de igual manera las botellas pues tampoco, igual puede, algunas empresas pues si se dedican a eso ..."

c) Conciencia atencional, que es cuando la conciencia atiende un hecho adaptándolo al momento actual. Ante esto, E1 dice "Tampoco lo hacemos, maas, ósea si se compra en la cafetería siempre va a ser desechable, desechable y desechable; entonces creo que por parte de nosotros pues no, no exigimos nada digamos que estamos poco, un poco desinteresados en esa parte".

Los entrevistados refieren un fenómeno de manera constante y con una conciencia de los tres tipos. El fenómeno se refiere al uso de envases de unicel, principalmente, platos, vasos, cubiertos, en el entendido de que la conciencia, son las vivencias, la conciencia fenomenológica es la vivencia intencional enmarcada en un tiempo (Mead, 1972).

En una conciencia intencional en la que se marca la conciencia actual, los entrevistados están conscientes de que identifican el fenómeno del consumo no sustentable de recipientes de unicel, así como del daño que provoca, en una muestra de conciencia potencial y la conciencia atencional al referirse al hecho de manera cotidiana y actual (Martínez, 1996). Por lo tanto, la comunidad se muestra consciente de sus actos, pero hay confusión en las acciones y el proceder de ellas, puesto que al parecer las normas que están establecidas no apoyan en la continuidad de dichas conductas.

En los resultados de la investigación cualitativa, la categoría de pragmatismo muestra que los individuos se comportan a partir de dos tipos de conductas, una conducta abierta y una conducta encubierta. La conducta abierta de los estudiantes, donde se involucra signos y símbolos que se relacionan con objetos físicos y sociales, tal como el pragmatismo lo refiere (Hans, 1998). Esa interacción entre los objetos y los símbolos hacen que se comporten de una u otra forma. Se manifestaron dos conductas que contempla el pragmatismo: la conducta 


\section{Revista Iberoamericana de las Ciencias Sociales y Humanísticas}

ISSN: $2395-7972$

abierta y la conducta encubierta. Con estas interpretan la realidad o sus representaciones sociales. Además, los sujetos entrevistados usan los símbolos y signos para manifestar lo que interpretan de su realidad y las acciones que llevan a cabo como conducta abierta (Charon, 2007). De este modo, los estudiantes universitarios asumen que consumen materiales que no deberían manifestando una conducta abierta y se justifican a través de simbolismos relacionados con la idea de "es lo que les ofrecen". Aquí se muestran hallazgos de los códigos correspondientes:

a) La conducta abierta corresponde a una conducta individual sobre lo que representan los objetos a una persona (Charon, 2007; Mead, 1972). Como E1 menciona “....lo que hacemos nosotros los estudiantes es comprar dentro de la universidad y no exigimos o no decimos pues no me sirvas en el unicel o no voy utilizar el popote, la pajilla como le llamen ooo los cubiertos así no porque tampoco nosotros pues traemos nuestros cubiertos o nuestro "lonche"

b) La conducta encubierta es la que las personas manifiestan de manera colectiva ante el estímulo de los símbolos que les representan los objetos (Charon, 2007; Mead, 1972) creando aseveraciones como la siguiente, E1: “...aunque digan que si algunas fábricas o empresas no son para nada reutilizables de igual manera las botellas pues tampoco, igual puede, algunas empresas pues si se dedican a eso ..."

De este modo, ha sido posible identificar la manera en que los individuos reconocen sus actos y sus maneras de conducirse, pero también ubican los estímulos que los llevan a esas conductas. En un sentido pragmático y tal como Hans (1998) refiere, los entrevistados recuerdan lo que les interesa, lo que les es útil, y todo en relación con la manera en que conectan todo con el mundo y con sus vivencias.

En relación a la categoría sobre interaccionismo simbólico, la investigación realizada dio a conocer la composición mostrada en la Tabla 3: 
Tabla 3. Categorización del interaccionismo simbólico

\begin{tabular}{|l|l|l|}
\hline Categoría & Sub-categoría & Código \\
\hline $\begin{array}{l}\text { Interaccionismo } \\
\text { simbólico }\end{array}$ & Comportamiento & $\begin{array}{l}\text { Interacción social } \\
\text { Hipertextualidad y múltiples } \\
\text { modalidades semióticas }\end{array}$ \\
$\begin{array}{l}\text { Campo } \\
\text { semántico }\end{array}$ & $\begin{array}{l}\text { Acciones sociales } \\
\text { Combinación de análisis } \\
\text { orientado textualmente con } \\
\text { un análisis de las imágenes } \\
\text { visuales }\end{array}$ \\
\hline
\end{tabular}

Fuente: Elaboracón propia, 2018. Basada en Blumer, 1969 y Rose, 1962

Con la Tabla 2 se muestra que los miembros de la comunidad universitaria interactúan con los símbolos que les son empáticos. Lo anterior, tanto en lo referente con el consumo a través de comportamientos y campos semánticos, como lo concerniente a la interacción social y las acciones sociales (Littlejohn y Foss, 2011) ya sea por consenso o por socialización. En este vaciado se muestran los códigos hallados:

a) La interacción social se percibe en los estudiantes universitarios, cuando se refieren a los mensajes que debieran ser usados en relación al consumo y la manera en que los hacen, con expresiones como E1: "Creo que actividades, actividades recreativas, foros, no te puedo decir que videos, ósea ósea como videos o imágenes que nos digan que esto está mal y que.. y que no se debe de hacer y que evitemos eeel desechable ooo el unicel... ok lo vemos pero realmente no nos invita de manera directa a dejar de hacerlo simplemente..."

b) Las acciones sociales, por otro lado, se muestran con la adaptación que se genera con base en la interpretación que hacen de la realidad y del entorno los universitarios, (Blumer, 1969) luego reflexionar y elegir sobre las diferentes formas de actuar (Rose, 1962). Esto se muestra en la declaración de A1: Pues me imagino campañas, solamente, campañas que, pues, ahora sí, que unos se estén vigilando ¿no? "oye no tiraste la basura bien” “oye sácala y pásala al bote”, solamente así, porque, pues no, llegan y la tiran y no se fijan en qué bote la echaron”. También en esta expresión se muestra lo que D1 dijo: “los mismos egresados, los mismos alumnos y claro los profesores investigadores hagan sus materiales y sean consumidos por el mismo público principalmente el interno y posteriormente por el externo". 


\section{Revista Iberoamericana de las Ciencias Sociales y Humanísticas}

ISSN: 2395 - 7972

Los públicos de la comunidad unviersitaria, estudiantes, administrativos y docentes, mostraron que la interacción social es un acto permanente e ininterrumpido tal como Mead (1972) lo refiere, conformada por la interpretación de un conjunto de símbolos no aislados, plagados de carga reconocibles por una comunidad (Blumer, 1969) que genera campos semánticos para establecer comunicación. De hecho los integrantes de la comunidad, en específico los docentes, refieren la sustentabilidad como una estrategia de interacción de símbolos.

Con respecto a la percepción que dan lugar a un campo semántico, se cita lo siguiente del sujeto E1: Bueno puede ser la compra de ... estos productos ... ajá la compra de estos mismos productos ... pero al decir consumo ... se me viene a la mente más, más bueno que sea macro no solo unnna pequeña porción ... del producto al decir consumo ... me imagino algo gigantesco, algo grande ... entonces creo que eso sería una representación gráfica ... creo que eso sería... ”además ... Ajá bueno si comprando cosas relacionadas al producto que te ... que sean amigables con el medio ambiente.

En cuanto a la categoría de consumo sustentable, los entrevistados muestran la relación con la sociedad, con el entorno (Littlejohn y Foss, 2011), con el consenso y la interaceión como explicación de la interacción social. Actúan por consenso y refieren la importancia de generar estrategias donde puedan identificar elementos relacionados con el consumo sustentable a través de símbolos y signos (Mead, 1972) que sean empáticos e inviten a acciones; esto es, que sean campos semánticos reconocibles como amigables con el medio ambiente. También argumentan que se consideren los diferentes tipos de públicos en el momento de pretender influir en el comportamiento de la comunidad de consumo.

Los resultados de la investigación determinaron cuatro dimensiones relacionadas con el consumo sustentable que se muestran en la Tabla 4: 
Tabla 4. Dimensiones del Consumo Sustentable

\begin{tabular}{|c|c|}
\hline Categoría & Dimensiones \\
\hline $\begin{array}{l}\text { Consumo } \\
\text { sustentable }\end{array}$ & $\begin{array}{l}\text { 1. Dimensión socioeconómica-ecológica } \\
\text { Acciones relacionadas con empleo, ingreso, ahorro de energía, } \\
\text { ahorro de agua. } \\
\text { 2. Dimensión fases del consumo } \\
\text { Acciones relacionadas con políticas públicas hacia el consumo } \\
\text { sustentable. } \\
\text { 3. Dimensión áreas del consumo } \\
\text { Acciones relacionadas con lo que se consume para satisfacer } \\
\text { necesidades indispensables. } \\
\text { 4. Dimensión impacto } \\
\text { Acciones relacionadas con consecuencias del consumo: alto } \\
\text { impacto y bajo impacto. }\end{array}$ \\
\hline
\end{tabular}

Fuente: Elaboración propia basada en Geiger et al., 2018, Alonso, 2011, Liu et al., 2015, Murphy, 2012, Heiskanen et al., 2014

Sin embargo, los entrevistados también manifiestan que $D 1$, “...cuando hay cuatro o cinco productos de algo, pero no hay una opción sustentable o no hay uno donde no haya un impacto (enfatiza) hacia pues la ecología, hacia el planeta...”, entonces ¿qué habría que hacer?

La categoría de consumo sustentable, en su dimensión sobre impacto y desde un enfoque pragmático, apegado al empirismo enfatiza que se debe ahondar en el impacto y la esencia del consumo sustentable, incluyendo una visión general significativa de las acciones domésticas (Geiger, Fischer y Schrader, 2017). El impacto de las acciones puede ser bajo o alto. El bajo impacto, si bien no deja una huella ecológica significativa, sí conforman hábitos o acciones que podrían significar algún beneficio. Los docentes llevan a cabo también algunas acciones que pueden tener un alto impacto. Es muy interesante que sí identifican que sus actos individuales hacen la diferencia y pueden dejar impactar a nivel macro.

a) El de bajo impacto, si bien no deja una huella ecológica significativa, son acciones individuales que sí podrían significar algún beneficio como el que $A l$, del sector administrativo dice: “...el (aceite) Nutrioli y el Capullo, supuestamente dañan menos al cuerpo, y por eso, entonces esos dos son los que más consumo. El sector estudiantil también se manifiesta al respecto, J, dice que “...el uso de estos productos que te acabo de mencionar...utilizar y reutilizar...los productos quee pues que ... manejamos día a día ... siempre con una mirada aaaa pues amigable con el medio ambiente ...que creo que sería eso... ”, también añadió “...en algún momento pude elegir entre una botella y otra porque era más delgada entonces 
por lógica si hay menos mmm... eee materia como tal va a tardar menos tiempo en degradarse o desintegrarse. También ofrecen algunas ideas que pudieran implementarse como E1 "Digo de igual manera interesar ...Y estar inmersos en la cafeterías; bueno va que ellos hagan su parte en no servir enn este tipo de productos que lo veo imposible es realmente es una utopía quiero pensar". Pareciera que los docentes llevan a cabo también algunas acciones que pueden tener un alto impacto como lo menciona D1 “...hay que tratar de que la basura vaya en bloques todo lo de cartón, todo lo de vidrio, en la situación del tetrapack tenerlo bien por separado ya sea que se lo lleve la basura o las personas que hacen sie... bueno que realizan esa recolección..." Es muy interesante que sí identifican que sus actos individuales hacen la diferencia, y pueden impactar a nivel macro, como Al dice “...separar, separar los botes, lo que es de aluminio, el plástico, el papel, este.. los residuos de comida..."

b) El de alto impacto, sugiere involucrar actores capaces de generar políticas públicas que deben ser atendidas por la sociedad y buscan hacer la diferencia en alterar el comportamiento del consumo sustentable (Perevochtchikova, 2013). Al respecto el docente D1 comenta “... la etiqueta de corrupción en México pues pesa mucho, el gobierno estaría en toda su facultad de decir bueno en cinco años o en un año ya está prohibida la venta de este tipo de plástico, sigo concentrado en ese asunto de la botella de agua paraa para agua, sin embargo sabemos que con cierta cantidad de dinero el gobierno dice bueno sigue vendiendo y vemos por donde más podemos hacer esta parte sustentable. Y si yo si le doy mucho peso al gobierno en esa situación, en ellos estaría el ejemplo incluso la solución para esta parte sustentable y con eso se evitarían las personas que consumieran desmedidamente X o Y producto”.

Otra manera de pensar en el alto impacto, tal como lo manifiesta Al que enfatiza “...el Medio Ambiente está dañado, se está dañando y pues va a tener, ahora si que, nietos, mis nietos, se les va a quedar un Medio Ambiente que pues ya no va a estar, ya no va a ser saludable...”. El sector académico se concentra en que debieran proponerse acciones para evitar más consumo. A esto el maestro D1 comenta “...recuerdo que en algún momento la universidad produjo sus computadoras emm fue un buen experimento...otra cuestión, es que para producir un litro de Coca Cola se necesitan 20 litros de agua, o para producir una 

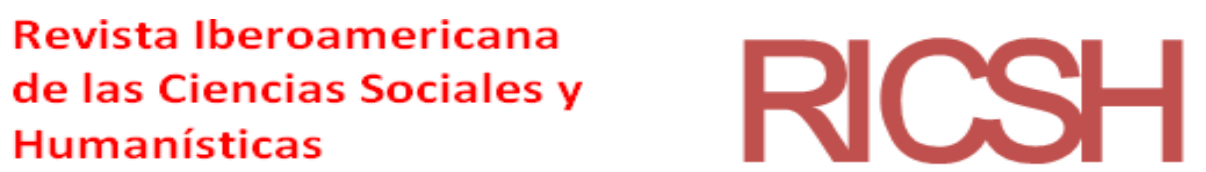

ISSN: $2395-7972$

computadora o una laptop se requieren, son una tonelada y media de agua que llegan todo ese proceso."

La investigación muestra que además de estar conscientes sobre sus acciones, el tema del impacto ambiental es algo que sí tienen considerado, y además identifican los efectos que esto implica. Los tres sectores parecen demostrar interés por lo que ocurre cuando toman una y otra opción, pero reconocen también que no siempre ponen de su parte, y que falta motivación o incentivos para colaborar de manera más comprometida.

En estos ámbitos hubo mayor respuesta debido a que se relacionan códigos tales como la seguridad, el nivel de vida, las preferencias, el empleo, el ingreso, el ahorro de energía, de agua y demás recursos como las políticas públicas, la adquisición, uso y eliminación o desecho de productos o materiales; también (Liu, Oosterveer y Spaargaren, 2015) con la sustentabilidad, los dominios o preferencias de consumo para satisfacer los diferentes tipos de necesidades. En este sentido, nuevamente resalta el uso de materiales que distinguen como dañinos, el unicel o el plástico, refiriendo las áreas de consumo como la cafetería del lugar donde estudian, o su propia casa. En el ámbito de sustentabilidad le dan fuerte importancia al ahorro de algunos recursos naturales, pero también refieren que deben implementarse estrategias (Perevochtchikova, 2013) para no solo hacer conciencia, sino desarrollar políticas que impulsen acciones en beneficio de la comunidad. De esta manera, las cuatro dimensiones son abordadas, desde un ámbito socioeconómico-ecológico, de fases y áreas de consumo, y desde el impacto, tal como lo refieren Geiger, Fischer y Schrader (2017).

Por su parte, el marketing, que es una actividad desarrollada en comunidad, en sociedad, y los hechos sociales constituyen una conciencia colectiva (Durkheim, 1998), se forma de valores, comportamientos, actitudes, costumbres, con la finalidad de seleccionar lo que mejor satisfaga las necesidades, para manifestar una conciencia individual pero que se convierta en colectiva e involucre emociones, sentimientos, costumbres.

De esta manera, la construcción de mensajes que persuadan hacia una conciencia en el consumo, menciona el docente D1 que “...tiene que ser un mensaje claro y a la vez tiene que ser un mensaje compacto. Ya en esta sociedad dinámica ...el mensaje tiene que ser en pocos segundos, porque la retención del público que en este caso el público meta yo lo estimo entre unos 18 a unos 35, es de aproximadamente de 17 a 12 segundos donde si no se logra esa atención se pierde la, se pierde misma y entonces habría que buscar ahí otra, otra forma... tiene que ser conciso no tiene que haber distractores me refiero a que el mismo mensaje tiene 


\section{Revista Iberoamericana de las Ciencias Sociales y Humanísticas}

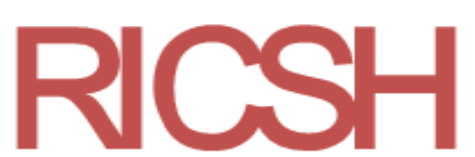

ISSN: $2395-7972$

que ser lo principal ...y la imagen tiene que ser un complemento, no ganarle la imagen al mensaje. Eee $;$ ? las palabras tienen que ser mиy тиy este muy puntuales tal vez incluir datos duros. Emm buscar que sea una persona o tal vez dos las que estén en ese mensaje donde se pueda hacer el complemento buscar un mensaje, aunque si es difícil que se pueda hacer para este tipo de público (su mirada está en un punto perdido mientras piensa lo que va a decir). De repente habría que segmentar mensajes en 18 a 25, después 25 a 35, 40 no caer en palabras como groserías, tal vez por querer jalar la atención del público que en este caso 18 a 25 ya son muy de palabras...fuertes ooo palabras gancho que llegan a desconcentrar, principalmente son esos, esos punto..."

a) La selectividad es una acción que contiene elementos de interacción simbólica (Sandoval, 1996), donde el consumidor es consciente de su elección ante diferentes alternativas (Perlo, 2006). Los estudiantes mencionan E1 “...videos o imágenes que nos digan que esto está mal y que... y que no se debe de hacer y que evitemos desechable el unicel... ok lo vemos, pero realmente no nos invita de manera directa a dejar de hacerlo simplemente..."

b) La satisfacción de necesidades es cuando se consume de manera consciente pero con la claridad de que es para reducir algo que se requiere (Mead, 1972). El maestro D1 dice que "...el consumo lo vemos ya como algo de mañana, tarde y noche hablando de comida, hablando de ropa, hablando de tecnología, es un consumo que lo hacemos de manera diaria, si, e incluso ya sobre fechas muy específicas donde pareciera que en esta fecha hay que pues consumir, hay que comprar, hay que gastar, hay que vender incluso..."

La investigación muestra que si bien, se perciben diferentes acciones para poder colaborar en beneficio del entorno, también muestran que lo que el mercado ofrece no es lo más adecuado en cuanto a influencia, a construcción del mensaje, a satisfacción de necesidades, y por ende, a la elección de materiales que no provoquen problemas a largo plazo. Por ello, sugieren hacer más trabajo en el sentido de relacionar más entidades en beneficio de la construcción de propuestas con una mayor mirada hacia la sustentabilidad.

La información que los entrevistados refieren, aborda fases de una estrategia que incluye los códigos, el público, los objetivos, las tácticas y los contenidos, donde se retoman aseveraciones dentro de lo manifestado en los resultados de la categoría de marketing semiótico. Esto es aplicando elementos simbólicos para la interacción del mensaje y empatía 


\section{Revista Iberoamericana de las Ciencias Sociales y Humanísticas}

ISSN: $2395-7972$

en la construcción de ellos, donde insisten en que el tiempo en que se muestra el mensaje es fundamental, pero también que lo mencionado debe ser identificable como una vivencia, algo que les ha sucedido o que saben de alguien a quien le ha sucedido, y por ende, decidan cambiar o se sientan invitados a tomar otras acciones. El storytelling podría mostrar la empatía con los diferentes tipos de públicos de la Facultad.

\section{Discusión}

A partir de un método descriptivo se hizo una revisión bibliohemerográfica de casos que existen sobre el proceso que se sigue en las propuestas de estrategias sobre consumo sustentable. Los hallazgos del instrumento cualitativo, confirmaron que el contexto donde se encuentran las comunidades universitarias sea apto para la aplicación de propuestas sobre consumo sustentable basados en el marketing semiótico a través del storytelling. La aplicación de entrevistas en profundidad a los sectores de la comunidad universitaria, permitió obtener la información necesaria para asegurar la pertinencia de llevar a cabo contenidos de storytelling que impulsen propuestas sobre el consumo sustentable dentro de este tipo de comunidades. Se considera que la base de la estructura de estos contenidos debe estar fundamentada en la narración de historias empáticas sobre las acciones sustentables y la manera en que se manifiesta el fenómeno en la práctica diaria del consumo, así como las diversas maneras en que se interactúa a través de significados que se han convertido en símbolos, capaces de ser compartidos para llevar a cabo comportamientos en beneficio del entorno.

En la interpretación cualitativa hecha sobre las diferentes categorías a priori se manifestaron algunas emergentes como el tipo de sector socioecónomico y el nivel académico al que se pertenece. Los resultados indican que miembros pertenecientes a un sector social y a un nivel académico específico perciben de manera diferente la realidad y la interpretan de modo distinto debido a estas diferencias en formación y nivel socioeconómico.

El docente entrevistado manifestó un significado sobre lo sustentable asociado con el consumo cultural, al parecer la sustentabilidad relacionada con el consumo requiere de mayor información y posicionamiento en la comunidad. El sector administrativo confunde continuamente acciones de consumo, con acciones de desecho y de uso, lo que conlleva a asociaciones de campos semánticos distintos y, por ende, a acciones no sustentables en sus 


\section{Revista Iberoamericana de las Ciencias Sociales y Humanísticas}

ISSN: $2395-7972$

comportamientos. Otro elemento identificado es que los administrativos confunden las representaciones gráficas con definiciones de consumo sustentable, mencionando que el consumo sustentable es lo que se plasma en algunos envases, por mencionar un ejemplo.

A partir de los resultados en las diversas categorías y dimensiones es posible ubicar la estrategia para desarrollar una storytelling en vías de un cambio de comportamiento hacia el consumo sustentable en comunidades universitarias en México. El lenguaje que debe usarse, el tipo de personajes que se van a representar, el lugar, tiempo y espacio donde se ubicarán los protagonistas y los hallazgos relacionados con las acciones sustentables, son elementos fundamentales para establecer bocetos y guías para la generación de historias necesarias para generar cambios de comportamiento a través del storytelling.

Las limitaciones de este estudio están asociadas a la resistencia que se manifiesta en el cambio de comportamientos. Si bien se han llevado a cabo diversos intentos por lograrlo, es justo ese el problema con el que se han enfrentado. Pareciera simple de llevar a cabo, pero los seres humanos responden a una serie de estímulos que, con la repetición de ello, se vuelven difíciles de cambiar. Es en ese punto donde se están presentando los diferentes problemas de aceptación de propuestas relacionadas con el beneficio del medio ambiente.

Por otro lado, las fortalezas están asociadas con la interacción entre perspectivas filosóficas, sociológicas, psicológicas, y metodológicas, en función del desarrollo de propuestas que desencadenen referentes innovadores y permitan a los públicos identificar nuevas formas de participación y colaboración en beneficio de la comunidad.

Las áreas de debilidad identificadas en el estudio fueron principalmente la heterogeneidad del público, por lo que se han iniciado los trabajos en públicos que amplían los perfiles; así como las categorías emergentes no contempladas en la investigación, como la falta de información básica sobre el concepto de sustentabilidad entre los miembros de la comunidad analizada.

La otra debilidad es la juventud del storytelling como estrategia de persuasión hacia el cambio de comportamientos sociales. Sin embargo, esta debilidad es una gran oportunidad para fomentar su uso y ser determinante en la solución de problemas de índole social que permitan el mejoramiento de la metodología y de sus alcances. 


\section{Conclusiones}

Dado que el objetivo del trabajo fue definir el tipo de estrategias que pudieran significar tanto empatía como efectividad para el envío de mensajes y actuar a favor del medio ambiente, se puede concluir que la estrategia del storytelling permite identificar emociones con acciones y por ello, permite al receptor establecer vínculos de empatía con lo que lee, escucha, observa, contrasta o revive. Por ello, esta estrategia logra conectar con grandes audiencias debido a que genera conexiones emocionales con las historias que se narran apegadas a situaciones reales que evocan identificación con quien hace la narración, y por ende, con el mensaje enviado. La narrativa usada es muy detallada, breve y mezcla diferentes tipos de recursos de contenido tales como imágenes, sonidos, videos. Así, permite una comunicación directa para que el consumidor se perciba como parte del mensaje y, por ende, se convierta en un protagonista de la historia que percibe.

Es importante entonces tomar en cuenta cuando se desarrollan estrategias persuasivas, que el storytelling conecte con las emociones, esto es, debe ser convincente y efectivo en su mensaje, entretener y generar interés, además de activar la imaginación y tocar en todo momento su lado más emotivo. Aunado a ello, generar un enlace con el mensaje que se desea emitir, de tal modo que se desee compartir con más y más individuos. Los elementos que deben incluirse en esta estrategia son drama, vinculación, inmersión, simplicidad, familiaridad y confianza en el narrador.

Este tipo de estrategia, el storytelling, sin duda es funcional ya que logra identificar a los consumidores con una situación en la cual se vean reflejados. Así, se crean narraciones en diversos géneros donde se muestren sueños, problemas, logros, amores, deseos, entre otros. Esto se manifiesta en personajes que sean creíbles, empáticos, honestos y porten elementos culturalmente reconocibles. La inmersión se logra al aplicar los elementos que generen expectación, ritmo, magia, sorpresa para atraer la atención hacia el contenido.

La trama puede desarrollarse de manera simple con acciones que sigan un tiempo y ubicando la historia en entornos semejantes para lograr familiaridad, bajo una narrativa lógica con un inicio, clímax y desenlace. Todo ello con el propósito de generar tal confianza hacia el personaje o el narrador, que el receptor se ubique en la disposición de llevar a cabo lo que la historia le sugiere. 
Así, la estrategia de storytelling cumple con los elementos para poder transformar los hallazgos de la aplicación cualitativa, en un conjunto de historias en las que se muestre a cada uno de los sectores de la comunidad universitaria las acciones que puede ejercer para tanto a favor como en contra del consumo sustentable. Los contenidos que deben abordarse en el desarrollo de esta herramienta, deben considerar situaciones que lleven a tomar conciencia de una situación determinada. Este propósito se logra con mostrar conductas donde personajes representativos de la comunidad de consumo elegida interactúa con acciones sociales empáticas en entornos representativos y cotidianos, demostrando su compromiso con la sustentabilidad.

Los personajes deberán ser totalmente creíbles, empáticos, con historias veraces, sueños, deseos, amores, problemas y logros que compartir a través de su construcción empática y honesta. Así, se trata de vincular a los narradores y personajes con los receptores. Y también, contar con producciones rítmicas, mágicas, sorpresivas y relevantes para atrapar la atención de las audiencias a través de un lenguaje simplista y de representar escenarios donde se vean reflejados.

De esta manera, los individuos de comunidades universitarias de consumo se verán reflejados en las historias vertidas en las narraciones del storytelling y podrán familiarizarse con los temas de consumo sustentable y generar una relación de confianza con los emisores y mensajes universitarios. El propósito de sensibilizar hacia causas solidarias como es el consumo sustentable puede llevar a cambios en la manera de actuar y en acciones para beneficio del contexto universitario. 


\section{Referencias}

Ajzen I., y Fishbein, M., (1980). Understanding attitudes and predicting social behavior. Englewood Cliffs: Prentice-Hall.

Alonso, L. E. (2008). Las políticas del consumo: transformaciones en el proceso de trabajo y fragmentación de los estilos de vida. Revista Española de Sociología (4), . Recuperado a partir de https://recyt.fecyt.es/index.php/res/article/view/64939

Barrio, J. (2015). La influencia de los medios sociales digitales en el consumo. La función prescriptiva de los medios sociales en la decisión de compra de bebidas refrescantes en España. Universidad Complutense de Madrid. Disponible en https://eprints.ucm.es/42339/1/T38702.pdf

Berger, L. y Luckmann, T. (2005 [1966]). La construcción social de la realidad. Buenos Aires: Amorrortu editores.

Bur, A. (2013). Marketing sustentable. Utilización del marketing sustentable en la industria textil y de la indumentaria. Cuadernos del Centro de Estudios en Diseño y Comunicación. 45, 133-142. Recuperado de https://dialnet.unirioja.es/servlet/articulo?codigo $=4200817$

Blumer, H. (1969). Simbolic interaccionism. Perspective and method. Englewood Cliffs, Nueva Jersey: Prentice-Hall.

Charon, J. M. (2007). Symbolic Interactionism. An Introduction, an Interpretation, an Integration. Nueva Jersey: Pearson Prentice Hall.

Cid Jurado, Alfredo (2002). El estudio de los objetos y la semiótica. Cuicuilco, 9(25),0. Recuperado de: https://www.redalyc.org/articulo.oa?id=351/35102511

Durán, M. (2012). El estudio de caso en la investigación cualitativa. Revista Nacional de Administración. 3(1 enero-junio):121-134. doi: 10.22458/rna.v3i1.477

Durkheim, E. (1998). Educación y Pedagogía. Ensayos y controversias. Buenos Aires, Argentina: Losada.

Fernández, E. M. (2018). Actitudes hacia la inclusión de universitarios con discapacidad. Desarrollo y validación de una escala basada en la Teoría de la Conducta Planificada. Electronic Journal of Research in Education Psychology 16(44):199-222. doi: 10.25115/ejrep.v16i44.1944

Geiger, S., Fischer, D., y Schrader, U. (2017). Measuring what matters in sustainable consumption research: an integrative framework for the selection of relevant 
behaviors Sustainable Development 26(1):18-33. https://doi.org/10.1002/sd.1688

Giddens, A. (2014). Sociología. España: Alianza Editorial.

González, L. (2016). ¿Del consumo sostenible a una economía circular? Revista CESCO de Derecho de Consumo, (17):179-91. Recuperado de http://www.revista.uclm.es/index.php/cesco.

Gurrieri, L., Govan J. B, y Cherrier, H. (2016). Controversial Advertising: Transgressing the Taboo of Gender-Based Violence. European Journal of Marketing, 50(7-8):144869. Recuperado de https://www.emerald.com/insight/content/doi/10.1108/EJM-092014-0597/full/html

Hans, J. (1998). El pragmatism y la teoría de la sociedad. Centro de Investigaciones Sociológicas (CIS). Madrid, España: Edit. Siglo XXI.

Heiskanen E, Mont, O., y Power K.A. (2014). A map is not a territory - making research more helpful for sustainable consumption policy. Journal of Consumer Policy. 37(1), 27-44. https://doi.org/10.1007/s10603-013-9247-8

Henninger, C. E., Panaviota. J., y Oates C.J. (2016). What Is Sustainable Fashion? Journal of Fashion Marketing y Gestión: An International Journal, 20(4):400-416. Doi: 10.1108/JFMM-07-2015-0052

Husserl, E. (1998). Invitación a la fenomenología. Barcelona, España: Paidós.

Le Roux, A., Thébault, M., Roy, Y. y Bobrie, F. (2016). Brand Typicality Impact on Brand Imitations Evaluation and Categorization. Journal of Product \& Brand Management 25(6):600-612. Doi: 10.1108/JPBM-07-2015-0923

Littlejohn, S. W., and Foss, K. A. (2011). Theories of human communication. Long Grove, Illinois. USA: Edit. Waveland. Disponible en https://books.google.com.mx/books?hl=en\&lr=\&id=dfUYAAAAQBAJ\&oi=fnd\&p g=PR3\&ots=aaAQPRY7tg\&sig=vSLTUaAwfRt2RW2LH6YW2Hnj4rs\&redir_esc= $\mathrm{y} \# \mathrm{v}=$ onepage $\& \mathrm{q} \& \mathrm{f}=$ false

Liu, W., Oosterveer, P., Spaargaren G. (2015). Promoting sustainable consumption in China: a conceptual framework and research review. Journal of Cleaner Production 134:1321. Doi: $10.1016 /$ j.jclepro.2015.10.124

Löbler, H. (2017). Human's relationship to nature - framing sustainable marketing. Journal of Services Marketing. 31, (1), 73-82. https://doi.org/10/1108/JSM-01-2016-0037 
López, I., Arriaga, A., y Pardo, M. (2018). La dimensión social del concepto de desarrollo sostenible: ¿La eterna olvidada?. Revista Española de Sociología. 27, 25-41. Recuperado de http://recyt.fecyt.es/index.php/res/article/view/65602

Martin, D., y Väistö, T. (2016) Reducing the attitude-behavior gap in sustainable consumption: a theoretical proposition and the American electric vehicle market, in Naresh K. Malhotra (ed.) Marketing in and for a Sustainable Society. Review of Marketing Research, 13, 193-214. Recuperado de http://books.google.com/books?vid:ISBN1786352818

Martínez, M. (1996). El comportamiento humano. México: Trillas.

Maddock, S., and Hill, B. (2016), "Bagels and doughnuts ... round food for every mood" food advertising discourses", British Food Journal., 118 (2), 327 - 342. https://www.proxydgb.buap.mx:2168/10.1108/BFJ-04-2015-0136

Sha, O., May, A., Londerville, J., and Ralston, C. E. (2007) Understanding gay consumers' clothing involvement and fashion consciousness. International Journal of Consumers Studies. 31 (5), 453-459. https//:doi.org./10.1111/j. 1470-6431.2007.00593.x

Mead, G. (2015). Mind, Self and Society. The University of Chicago Press. USA. DOI: 10.7028/chicago/9780226112879.001.0001

Mickelsson, K. J. (2017). Running is my boyfriend": consumers' relationships with activities. Journal of Services Marketing, 31(1), 24 - 33, doi: 10.1108/JSM-03-2016-0108

Murphy, K. (2012). The social pillar of sustainable development: a literature review and framework for policy analysis. Sustainability: Science, Practice, and Policy. 8(1): 15-29. Doi: 10.1080/15487733.2012.11908081

Osorio, F. (1998). El método fenomenológico. Cinta de Moebio, 3. Recuperado de http://www.redalyc.org/pdf/101/10100307.pdf

Paris, J. C. (2015). Aplicación del cuadrado de Greimas a los cuatro aspectos esenciales del marketing. Poliantea, 11 (21):61-102. Doi: 10.15765/plnt.v11i21.704

Perevochtchikova, M. (2013). La evaluación ambiental y la importancia de los indicadores ambientales. Gestión y política pública. 22 (2) 283-312. Recuperado de http://www.scielo.org.mx/scielo.php?pid=S1405$10792013000200001 \&$ script=sci_arttext\&tlng=pt

Perlo, Claudia L. (2006). Aportes del interaccionismo simbólico a las teorías de la organización. Invenio, 9 (16), 89-107. Recuperado de: 
https://www.redalyc.org/articulo.oa?id=877/87701607

Peterson, M., and Lunde, M. (2016), Turning to Sustainable Business Practices: A Macromarketing Perspective, in Naresh K. Malhotra (ed.) Marketing in and for a Sustainable Society. Review of Marketing Research. 13, 103 - 137. Emerald Group Publishing Limited. Recuperado de: https://doi/10.1108/S1548643520160000013013

Presi, C., Maehle, N., y Kleppe, I. A. (2016) Brand selfies: consumer experiences and marketplaces conversations., European Journal of Marketing, 50 (9/10), 1814 - 1834. Recuperado de https://doi/10.1108/EJM-07-2015-0492/full/html?fullSc=1

Raghda El Ebrashi, (2013) Social entrepreneurship theory and sustainable social impact. Social Responsibility Journal. 9 (2), 188-209, doi: 10.1108/SRJ-07-2011-0013

Rodríguez, D. y Rabadán, B. (2015). Proceso de decisión del consumidor: factores explicativos del visionado de películas en sala de cine de los jóvenes universitarios españoles. Universitat Internacional de Catalunya. Recuperado de:https://www.tesisenred.net/bitstream/handle/10803/146251/David_Rodriguez_R abad\%C3\%A1n\%20Benito.pdf?sequence=1\&isAllowed $=\mathrm{y}$

Rokka, J., y Canniford, R. (2016) "Selfies Heterotopian: how social media destabilizes Brand assemblages. European Journal of Marketing, 50 (9/10), 1789 - 1813. Recuperado de https://www.emerald.com/insight/publication/issn/0309-0566/vol/50/iss/9/10

Rose, A. M. (1962). Human behavior and social processes: An interactionist approach. Boston: Houghton Mifflin.

Saldívar, A., Barrera, A., Rosales, P., Villaseñor E. (2002). Tres metodologías para evaluar la sustentabilidad: 10 años después de Río. Journal Investigación Económica. 62 (242), 159-185. Recuperado de: http://www.scielo.org.mx/pdf/ineco/v62n242/01851667-ineco-62-242-159.pdf

Salmón, C. (2008). La fábrica de inventar historias, y formatear las mentes. Francia: Península.

Sandoval, C. (1996). Investigación cualitativa. Colombia: ICFES-ACIUP.

Schiffman, L., y Kanuk, L. (2005). Comportamiento del consumidor. México: Prentice Hall.

Stake. R. (2005). Qualitative case studies. En N. K. Denzin y Y. S. Lincoln (Eds.). The SAGE handbook of qualitative research (pp. 443-466). Thousand Oaks, CA: Sage. 
Su J., y Chang, A. (2018). Revista internacional de gestión de distribución y venta minorista. 46, (1). 90.107. https://doi.org/10.1108/IJRDM-01-2016-0015

\begin{tabular}{|l|l|}
\hline Rol de Contribución & Autor (es) \\
\hline Conceptualización & Andrea Estupiñán Villanueva \\
\hline Metodología & Edith Molina Carmona \\
\hline Software & No aplica \\
\hline Validación & "Igual” Andrea Estupiñán Vilanueva, Edith Molina Carmona \\
\hline Análisis Formal & "Igual” Andrea Estupiñán Vilanueva, Edith Molina Carmona \\
\hline Investigación & Andrea Estupiñán Vilanueva \\
\hline Recursos & Edith Molina Carmona \\
\hline Curación de datos & "Igual” Andrea Estupiñán Vilanueva, Edith Molina Carmona \\
\hline $\begin{array}{l}\text { Escritura - Preparación } \\
\text { delborrador original }\end{array}$ & "Igual” Andrea Estupiñán Vilanueva, Edith Molina Carmona \\
\hline Escritura - Revisión y edición & "Igual” Andrea Estupiñán Vilanueva, Edith Molina Carmona \\
\hline Visualización & Rosario López Álvarez \\
\hline Supervisión & "Igual” Andrea Estupiñán Vilanueva, Edith Molina Carmona \\
\hline Administración de Proyectos & "Igual” Andrea Estupiñán Vilanueva, Edith Molina Carmona \\
\hline Adquisición de fondos & Andrea Estupiñán Vilanueva \\
\hline
\end{tabular}

